\title{
亶 \\ Pododermatite associada à piometra em coelho doméstico (Oryctolagus cuniculus): relato de caso
}

\author{
[Pododermatitis associated with pyometra in a domestic rabbit \\ (Oryctolagus cuniculus): case report]
}

\section{"Relato de Caso/Case Report"}

\author{
Claudio Douglas Oliveira Guimarães ${ }^{1 *}$, Mário José Costa Carneiro $^{2}$, Aline Lobão Silva ${ }^{2}$, Dandara \\ Vitoria Alves Dias ${ }^{2}$, Jean Caio Figueiredo de Almeida² ${ }^{2}$, Adriano Pereira Leão ${ }^{2}$, Maridelzira \\ Betânia Moraes David ${ }^{3}$, Luiz Fernando Moraes Moreira ${ }^{3}$
}

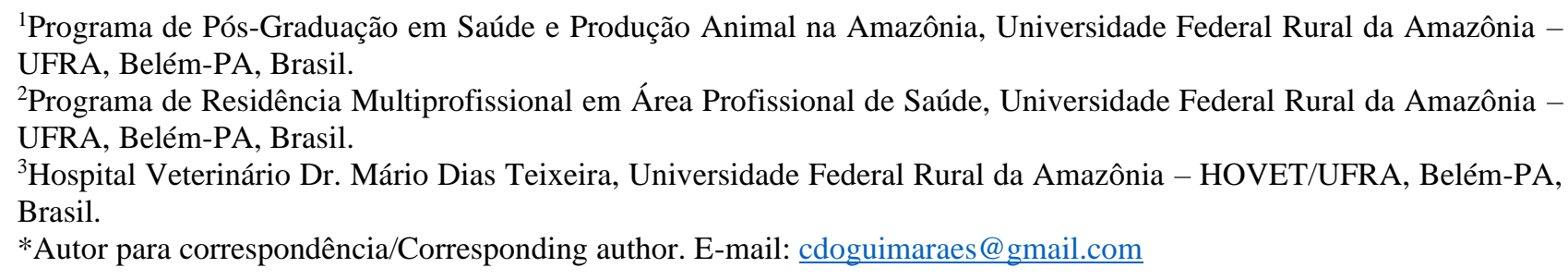

\section{Resumo}

Este trabalho tem como objetivo relatar um caso de pododermatite bacteriana em coelho doméstico com quadro concomitante de piometra. Foi atendido no ambulatório de animais selvagens anexo ao Hospital Veterinário Professor Mário Dias Teixeira da Universidade Federal Rural da Amazônia, um coelho doméstico (Oryctolagus cuniculus) fêmea, adulta, da raça Nova Zelândia, pesando 2,248kg, tendo como queixas principais diarreia, disúria, emagrecimento, secreção vaginal e presença de abscessos nos quatro membros. Após realização de exame ultrassonográfico, foi diagnosticada com piometra, sendo indicada ovariosalpingohisterectomia terapêutica e drenagem dos abscessos podais. Durante o transoperatório, foi coletado material do interior dos abscessos para análise microbiológica e realização de antibiograma, sendo identificada a presença da bactéria Staphylococcus sp. Posteriormente, foi indicado tratamento com antibiótico e anti-inflamatório sistêmicos, ambos por via oral, além de tratamento tópico com pomada antibiótica e cicatrizante, porém, o animal foi a óbito cinco dias após o procedimento. Este relato ilustra que as condições inadequadas de manejo podem resultar em diversas patologias, a exemplo da pododermatite. Além disso, neste caso, o prognóstico era reservado, especialmente pela condição clínica da paciente, agravada pela presença de piometra e, possivelmente, instalação de septicemia.

Palavras-chave: Lagomorpha; infecção; reprodução.

\begin{abstract}
This work aims to report a case of bacterial pododermatitis in a domestic rabbit also affected by pyometra. A female domestic rabbit (Oryctolagus cuniculus), New Zealand, weighing $2.48 \mathrm{~kg}$ was treated at the outpatient clinic attached to the Veterinary Hospital Professor Mário Dias Teixeira of the Federal Rural University of the Amazon, having as main complaints diarrhea, dysuria, weight loss, vaginal secretion, and presence of abscesses in the four limbs. After ultrasound examination, pyometra was diagnosed, and therapeutic ovariohysterectomy and drainage of the foot abscesses were indicated. During the intraoperative period, material from inside the abscesses was collected for microbiological analysis, antibiogram was performed, and the presence of the bacterium Staphylococcus sp. was identified. Subsequently, treatment with antibiotic and systemic anti-inflammatory drugs, both oral and in addition to topical treatment with antibiotic and healing ointment, was indicated, but the animal died five days after the procedure. This report illustrates that inadequate management conditions can result in several pathologies, such as pododermatitis. In addition, in this case, the
\end{abstract}


prognosis was reserved, especially because of the patient's clinical condition, aggravated by the presence of pyometra and, possibly, septicemia.

Keywords: Lagomorpha; infection; reproduction.

\section{Introdução}

A pododermatite, também chamada de bumblefoot devido às lesões que provoca e por envolver outros tecidos além da pele, acomete vários grupos animais, especialmente aves (psitacídeos), lagomorfos (coelhos) e roedores (porquinho-da-índia). Trata-se de uma afecção caracterizada por inflamação, edema, eritema, hiperqueratose, ulceração e, muitas vezes, formação de abscessos na face plantar da extremidade podal ou dos dígitos (Samour, 2006; Ackermann e Redig, 2009; Hawkins e Bishop, 2012).

Em coelhos domésticos (Oryctolagus cuniculus), a pododermatite é comumente chamada de jarretes doloridos, doença dos jarretes ou ferida dos jarretes e cursa com dermatite crônica granulomatosa e ulcerativa da face plantar do metatarso e, ocasionalmente, da face palmar do metacarpo e das superfícies falangeanas das extremidades podais dos membros (Banks et al., 2010; Hess e Tater, 2012).

Os coelhos não possuem coxins plantares como outros mamíferos. Ao invés disso, apresentam uma camada de pelo denso que cobre os dígitos das extremidades anteriores e posteriores e na região metatársica, de modo que quando estão na posição de repouso, as superfícies plantares desde os dígitos ao jarrete ficam em contato com o chão (Donelly e Vella, 2012). Este fato associado ao confinamento dos animais em jaulas pequenas com pavimentos ásperos de cimento, de arame ou com carpetes ásperos e camas úmidas e sujas predispõe a ocorrência da doença (Hess e Tater, 2012).

A pododermatite, quando não tratada, pode infeccionar levando ao aparecimento de abscessos e úlceras com a ferida podendo se propagar e atingir tendões e ossos (Vilardo, 2007), tal como relatado por Pessoa et al. (2011) em um caso grave de osteomielite com exuberante reação osteolítica em membros torácicos em um coelho após instalação de pododermatite ulcerativa.

Alguns autores defendem uma predisposição racial, principalmente naquelas raças com a pele das almofadas plantares mais finas e delicadas, tais como os coelhos pertencentes à raça Rex, cujas extremidades estão providas de pelos macios e curtos, conferindo pouca proteção à região (Hess e Tater, 2012). Já outros autores (Hess e Tater, 2012; Blair, 2013) afirmam também que o peso pode ser um fator determinante para o desenvolvimento da doença, uma vez que raças corpulentas podem manter uma pressão extra sobre os membros devido ao sobrepeso, da mesma forma que fêmeas gestantes, levando a alterações na fisiologia normal de suporte de peso, podendo resultar em isquemia e necrose em região podal. Nessas áreas, pode-se instalar infecção bacteriana secundária, geralmente ocasionada por Staphylococcus aureus ou Pasteurella multocida (Blair, 2013).

Numa fase mais avançada da doença, o paciente apresenta-se agitado, com algum grau de anorexia e o processo de cicatrização é extremamente difícil, podendo levar à infecção do sistema linfático e septicemia (Van Praag, 2014).

O diagnóstico é feito com base nos sinais clínicos, citologia das lesões, cultura bacteriana e exame radiográfico dos membros, a fim de verificar a existência de osteomielite (Hess e Tater, 2012). Para o tratamento, pode-se realizar debridamento e limpeza das lesões, administrar antibioticoterapia tópica e sistêmica e proteger com bandagem (Graham, 2004; Paterson, 2006). Recomenda-se, ainda, que os animais sejam mantidos em locais protegidos de superfícies abrasivas e forrados com material macio (Vilardo, 2007).

Outro tipo de afecção em coelhos que geralmente apresenta envolvimento bacteriano é a piometra, cuja fonte de microrganismos é a microbiota normal da vagina, os quais penetram para o interior do útero durante o proestro e estro (Carpenter, 2005). Assim como nas pododermatites, os principais agentes bacterianos envolvidos no processo são Pasteurella sp., Staphylococcus sp. e Listeria sp., porém uma grande variedade de enterobactérias Gramnegativas também pode estar envolvida (Harkness e Wagner, 1993; Rosenthal, 2001).

Ao exame físico de coelhas acometidas por piometra pode-se observar depressão, desidratação, aumento palpável do útero e corrimento vaginal, com aumento ou não de temperatura retal (Paul-Murphy, 1997; Ettinger e 
Feldman, 2004). A cirurgia de ovariossalpingohisterectomia é o tratamento de eleição para resolução desta afecção, no entanto, por ser uma patologia considerada rara em coelhas, não se sabe qual a porcentagem de morbidade e de mortalidade envolvendo esta espécie (Rosenthal, 2001; Ettinger e Feldman, 2004). Da mesma forma que ocorre na pododermatite, a piometra pode evoluir para septicemia e, se não tratada corretamente e precocemente, choque, hipotermia e colapso (Ettinger e Feldman, 2004). Este trabalho tem como objetivo relatar um caso de pododermatite bacteriana em um coelho doméstico acometido também por piometra.

\section{Descrição do Caso}

Um coelho doméstico (Oryctolagus cuniculus) fêmea, adulto, da raça Nova Zelândia, com massa corporal de $2,248 \mathrm{~kg}$, foi atendido no ambulatório de animais selvagens anexo ao Hospital Veterinário Professor Mário Dias Teixeira, da Universidade Federal Rural da Amazônia no dia 04 de julho de 2017, tendo como principais queixas a presença de fezes diarreicas, secreção vaginal, lacrimejamento ocular e paresia de membros anteriores há uma semana. Durante a anamnese verificou-se que o animal era mantido em gaiola de ferro durante a noite e, ao longo do dia, permanecia solto no quintal para banhos de sol. A alimentação consistia em ração comercial, repolho e cenoura, porém, há uma semana vinha apresentando anorexia, emagrecimento e disúria. Ao exame clínico, foi observado que o paciente apresentava apatia e sinais de emaciação, seborreia difusa, crostas com acúmulo de sujeira em região da cauda, desidratação moderada (8 a $10 \%$ ), mucosas hipocoradas, secreção vaginal mucopurulenta, paresia de todos os membros associada à presença de abscessos em região plantar e palmar dos mesmos. Posteriormente, foi realizado exame ultrassonográfico, o qual indicou a presença de aumento de cornos uterinos $(2,2 \mathrm{~cm}$ de diâmetro) contendo conteúdo luminal anecoico e heterogêneo particulado, bem como paredes irregulares e espessadas, sugestivo de piometra (Figura 1).

A partir da anamnese, avaliação clínica e estado geral do animal, optou-se por cirurgia de ovariosalpingohisterectomia $(\mathrm{OSH})$ terapêutica e drenagem dos abscessos podais. A colheita de sangue foi comprometida devido à condição clínica do paciente, impossibilitando a realização de hemograma e perfil bioquímico sérico, sendo indicada fluidoterapia de reposição durante o préoperatório, por via parenteral no volume total de $100 \mathrm{~mL}$ de Ringer com Lactato associado a $20 \mathrm{~mL}$ de solução de Hertavitå, por 4 horas. Além disso, foi instituída terapia antibiótica e anti-inflamatória com enrofloxacino $2,5 \%$ na dose de $10 \mathrm{mg} / \mathrm{kg}$ e com meloxicam $0,2 \%$ na dose de $0,02 \mathrm{mg} / \mathrm{kg}$, respectivamente, ambos por via intramuscular, em dose única como medicação pré-operatória.

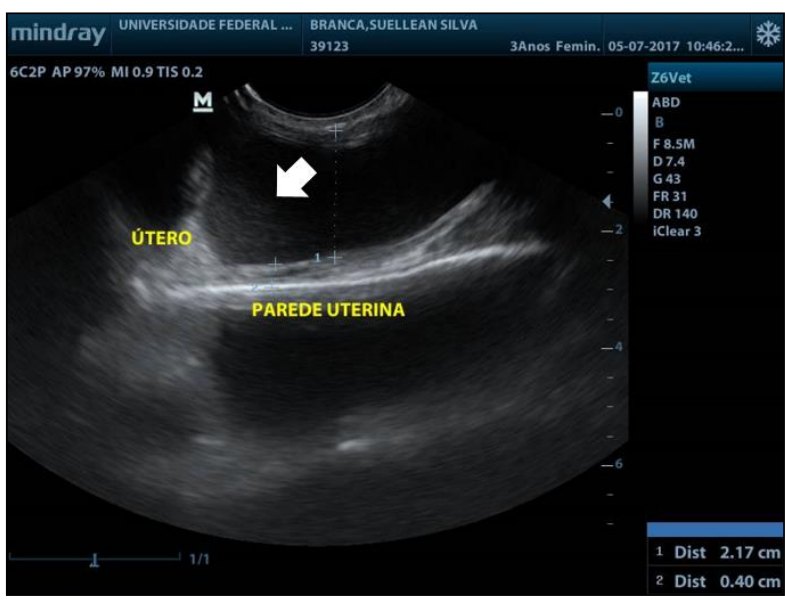

Figura 1. Útero de coelha (Oryctolagus cuniculus) apresentando dimensões aumentadas com conteúdo luminal anecoico (seta) constituído por material particulado em suspensão.

A indução anestésica foi realizada utilizando associação de cloridrato de cetamina $10 \%$ e midazolam $(5 \mathrm{mg} / \mathrm{mL})$ nas doses de 20 e $1 \mathrm{mg} / \mathrm{kg}$, respectivamente, por via intramuscular profunda no músculo quadríceps. Após diminuição dos reflexos palpebrais e miorrelaxamento, o paciente foi mantido em plano anestésico com isofluorano administrado em máscara de oxigênio acoplada ao focinho (Figura 2). O procedimento cirúrgico seguiu técnica de OSH descrita por Fossum (2014).

Durante o procedimento cirúrgico, foi realizada limpeza dos membros com solução de iodopovidona e, logo após, coleta do material presente no interior dos abscessos, o qual apresentou-se como coleção pastosa amarelada e de odor fétido (Figura 3), presente em região plantar e palmar de todos os membros, cujo conteúdo foi acondicionado em tubo tipo Falcon estéril, prontamente encaminhado ao laboratório de microbiologia clínica da Universidade Federal Rural da Amazônia para realização de exame de cultura e sensibilidade microbiana. Ao término do procedimento, foi realizada limpeza da ferida operatória e das áreas afetadas com solução antisséptica de clorexidina $2 \%$, sendo coberto com gaze, atadura e esparadrapo. Para o pós-operatório 
foi prescrito enrofloxacino e cetoprofeno nas doses de $10 \mathrm{mg} / \mathrm{kg}$ e $1 \mathrm{mg} / \mathrm{kg}$, respectivamente, por via oral por quatro dias, a cada 24 horas, além de limpeza das lesões com solução de digliconato de clorexidina e aplicação de Vetaglós pomada®, sendo recomendada troca diária.

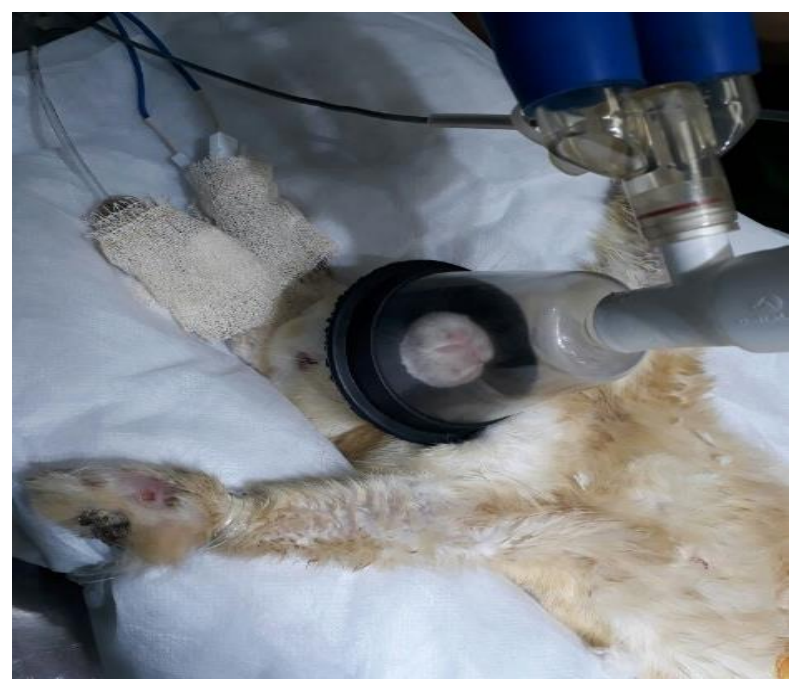

Figura 2. Paciente posicionado em decúbito dorsal e mantido em plano anestésico com isofluorano administrado em máscara de oxigênio.

A amostra coletada foi inoculada em placas de Petri contendo meios de Ágar sangue, Ágar MacConkey e Caldo Cérebro-Coração e, em seguida, incubadas em aerobiose em estufa a $37^{\circ} \mathrm{C}$, com crescimento e leitura em 24 horas. A morfologia das bactérias isoladas foi verificada por meio da coloração de Gram e microscopia óptica, sendo observadas bactérias Gram positivas e reativas ao teste de catalase, identificadas como Staphylococcus sp. O teste de sensibilidade microbiana foi realizado utilizando-se discos de difusão de antibióticos que acusaram resistência à Rifampicina, Penicilina G, Oxacilina, Cefotaxima, Amicacina, Gentamicina e sensibilidades à Nitrofurantoina, Ciprofloxacina, Norfloxacina, Sulfazotrim e Cloranfenicol.

Devido ao custo elevado do exame de cultura e antibiograma, os tutores autorizaram apenas o exame de cultura e antibiograma das amostras dos abscessos plantares e não autorizaram a realização da análise microbiológica do conteúdo uterino, o que impossibilitou a identificação de possíveis agentes microbianos envolvidos na piometra.

Neste caso, o paciente foi liberado para continuar o tratamento em casa, uma vez que o Hospital Veterinário em questão não dispõe de internação. Porém, o paciente foi a óbito cinco dias após a cirurgia, não sendo autorizada a realização da necropsia pelos tutores devido aos fortes laços afetivos com o animal.

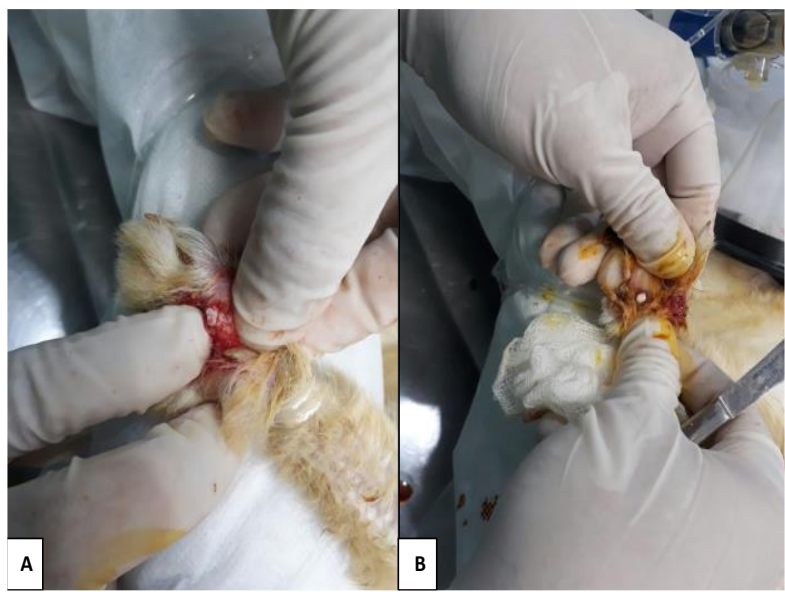

Figura 3. Drenagem para coleta de material purulento em região digital (A) e plantar (B) do membro anterior direito de coelho doméstico (Oryctolagus cuniculus) com pododermatite.

\section{Discussão}

Levando em consideração que a condição clínica do paciente é fator relevante para a instalação da pododermatite em pequenos mamíferos (Blair, 2013), o animal do presente relato apresentou prognóstico reservado, visto que sua condição clínica era desfavorável a uma boa recuperação devido ao quadro de desnutrição, desidratação e apatia.

Blair (2013) ressalta que os sinais clínicos e os achados do exame físico são importantes para a identificação de pododermatite e podem incluir alopecia podal, eritema, erosões, edema e claudicação, todos bem identificados no presente estudo, caracterizados especialmente pela relutância do paciente em andar.

A colonização das lesões por agentes bacterianos é muito comum e pode estar relacionada às condições inadequadas de higiene dos recintos de criação (Blair, 2013). Nesses casos, infecções por Staphylococcus aureus e Pasteurella multocida são frequentemente identificadas (Harcourt-Brown, 2002) e as úlceras infectadas progridem para abscessos cobertos com pústulas fibróticas e hiperqueróticas secas e soltas (Hess e Tater, 2012). No presente relato foi identificado que Staphylococcus sp. estava presente no material purulento coletado dos abscessos plantares e palmares, corroborando com a descrição dos autores supracitados.

O tratamento da pododermatite consiste na resolução da causa inicial, desbridamento e limpeza das lesões associado à antibioticoterapia tópica e sistêmica (Paterson, 2006), tal como 
adotado para o caso em questão. Cultura e testes de sensibilidade bacteriana devem ser realizados sempre que possível, a fim de conduzir a melhor terapia antibiótica (Hess e Tater, 2012). No presente relato foram realizados cultura e antibiograma das lesões podais, porém a paciente foi a óbito antes do resultado dos mesmos.

Concomitante ao quadro de pododermatite, a paciente também foi diagnosticada com piometra, o que pode ter resultado no quadro debilitante apresentado pelo animal. Neste caso, o histórico de secreção vaginal relatado pela tutora foi imprescindível para auxiliar no diagnóstico de piometra, uma vez que a urina normal do coelho possui porfirinas e apresenta coloração que varia do amarelo ao vermelho alaranjado ou marrom, assemelhando-se a pus ou sangue, podendo mascarar a presença de infecção uterina nesses animais e dificultar o diagnóstico de infecções do trato genito-urinário (Harkness e Wagner, 1993).

Vale ressaltar que, neste relato, a associação entre infecção podal e uterina pode ter levado a um quadro de septicemia, tal como afirma Ettinger e Feldman (2004), o qual enfatizam que, nestes casos, pode haver choque e colapso. Embora a piometra seja considerada rara em coelhos, na prática da clínica de animais exóticos observa-se prevalência moderada em decorrência da maior longevidade dos animais mantidos em cativeiro e do maior acesso ao atendimento veterinário especializado (Harkness e Wagner, 1993).

Não foi possível realizar análise microbiológica do conteúdo uterino, porém, a antibioticoterapia sistêmica realizada com enrofloxacino foi instituída especialmente devido à sua reconhecida eficácia contra bactérias Gram positivas (Spinosa, 2011), a exemplo do microorganismo Staphylococcus sp., identificado a partir das lesões podais, além de apresentar bons resultados contra infecções do trato genitourinário, tal como observada por Freitas (2011).

\section{Conclusão}

Este relato pode ilustrar que as condições inadequadas de manejo, podem resultar em um conjunto de afecções, nesse caso o desenvolvimento da pododermatite. Além disso, podemos pressupor que a condição geral do paciente, também acometido por piometra, pode influenciar diretamente no prognóstico do caso, cujos sinais foram observados no exame físico. Sendo assim, ressalta-se a importância do histórico e exame clínico detalhado na medicina de pequenos mamíferos, a fim de identificar eventuais patologias associadas e aumentar as chances de sucesso na resolução do caso.

\section{Conflito de interesse}

Os autores declaram não existir conflito de interesse.

\section{Agradecimentos}

À equipe de veterinários residentes $\mathrm{e}$ técnicos do HOVET-UFRA pelo apoio durante o tratamento do paciente.

\section{Referências}

Ackermann, J.; Redig, P. Raptors. In: Tully, T.N.; Dorrestein, G.G.M.; Jones, A.K. Handbook of avian medicine. $2^{\text {nd }}$ ed. Oxford: Saunders, 2009. p.180-214.

Banks, R.A.; Doss, S.D.; Sharp, J.M.; Vanderford, V.A. Exotic small mammal care and husbandry. EUA, Iowa: Willey-Blackwell, 2010. 192p.

Blair, J. Bumblefoot: A comparison of clinical presentation and treatment of pododermatitis in rabbits, rodents and birds. Veterinary Clinics Exotic Animal, 16(3): 715-735, 2013. Carpenter, J.W. Exotic Animal Formulary, $3^{\text {rd }}$ ed. St. Louis: Saunders, 2005. 412p.

Donelly, T.M.; Vella, D. Basic Anatomy, Physiology and Husbandry. In: Quesenberry, K.E.; Carpenter, J.W. Veterinary Clinics of North America: Exotic Animal Practice. Ed. Missouri, EUA: Elsevier Saunders, 2012. p.157-173.

Ettinger, S.J.; Feldman, E.C. Tratado de Medicina Interna Veterinária - Doenças do Cão e do Gato, $5^{\text {a }}$ ed. Rio de Janeiro: Guanabara Koogan, 2004. p.1632-1635.

Fossum, T.W. Cirurgia de pequenos animais, 4 ed. Rio de Janeiro: Elsevier, 2014. 1640p.

Graham, J.E. Rabbit wound management. Veterinary Clinics of North America: Exotic Animal Practice, 7(1): 37-55, 2004.

Freitas, L.R.; Silva, A.C.R.; Stela, A.E.; Portilho, E.F. Agentes causadores de infecções urinárias em cães em Rio Verde-GO: ocorrência e determinação da sensibilidade a antimicrobianos. Pubvet, 5(26): 1-9, 2011.

Harcourt-Brown, F. Textbook of Rabbit Medicine. $1^{\text {st }}$ ed. London: Butterworth Heinemann, 2002, 436p. 
Harkness, J.E.; Wagner, J.E. Biologia e clínica de coelhos e roedores. $3^{\text {a }}$ ed. São Paulo: Rocca, 1993. 238p.

Hawkins, M.G.; Bishop, C.R. Disease problems of guinea pigs: dermatologic diseases. In: Quersenberry, K.; Carpenter, J. Editors. Ferrets, rabbits, and rodents: clinical medicine and surgery. $3^{\text {rd }}$ ed, St Louis: Saunders, 2012. p.295-310.

Hess, L.; Tater, K. Dermatologic diseases. In: Quersenberry, K.; Carpenter, J. Editors. Ferrets, rabbits, and rodents: clinical medicine and surgery. $3^{\text {rd }}$ ed, St Louis: Elsevier Saunders, 2012, p.232-244.

Paterson, S. Skin Diseases of Exotic Pets. $1^{\text {st }}$ ed, Iowa, EUA: Wiley-Blackwell, 2006. 344p.

Paul-Murphy, J. Rabbits reproductive and urogenital disorders. In: Hillyer, E.V.; Quesenberry, K.E. Ferrets, Rabbits, and Rodents - Clinical Medicine and Surgery. Philadelphia: WB Saunders, 1997. p.202-211.

Pessoa, C.A.; Rodrigues, M.A.; Prazeres, R.F.; Fecchio, R.S. Osteomielite secundária à pododermatite ulcerativa em coelho: Relato de caso. Revista de Educação Continuada em Medicina Veterinária e Zootecnia do CRMV-SP, 9(2): 43-43, 2011.

Rosenthal, K.L. Bacterial infectious diseases in ferrets and rabbits. Proceeding of the Atlantic Coast Veterinary Conference. 2001. Disponível em: < https://www.vin.com/apputil/content/defaulta dv1. $\operatorname{aspx}$ ? $\mathrm{id}=3844050 \& \mathrm{pid}=11131 \&>$.

Acesso em: 10 jan. 2018.

Samour, J. Management of Raptors. In: Harrison, G.J.; Lightfoot, T.L. Clinical Avian Medicine, Palm Beach: Spix Publishing, 2006. p. 915-956.

Spinosa, H.S. Farmacologia aplicada à medicina veterinária. $5^{\mathrm{a}}$ ed. Rio de Janeiro: Guanabara Koogan, 2011. 738p.

Van Praag, E. Pododermatitis, a difficult problem in rabbits. 2014. Disponível em: < https://www.researchgate.net/publication/322 921675_Pododermatitis_a_difficult_problem _in_rabbits>. Acesso em: 10 jan. 2018.

Vilardo, F.E.S. Lagomorpha (coelho, lebre, lebreassobiadora). In: Cubas, Z.S.; Silva, J.C.R.; Catão-Dias, J.L. Tratado de animais selvagens - medicina veterinária. $1^{\mathrm{a}} \mathrm{ed}$. São Paulo: Roca, 2007. p.415-431. 